\section{BMJ Global Health}

\title{
'The nurse did not even greet me': how informed versus non-informed patients evaluate health systems responsiveness in South Africa
}

\author{
Dumisani MacDonald Hompashe (D) , ,2 Ulf-G Gerdtham (D) , ${ }^{3}$ \\ Carmen S Christian (D) , Anja Smith (D) , ${ }^{2}$ Ronelle Burger (D) ${ }^{2}$
}

To cite: Hompashe DM, Gerdtham U-G, Christian CS, et al. 'The nurse did not even greet me': how informed versus non-informed patients evaluate health systems responsiveness in South Africa. BMJ Global Health 2021;6:e004360. doi:10.1136/ bmjgh-2020-004360

Handling editor Seye Abimbola

- Additional supplemental material is published online only. To view, please visit the journal online (http://dx.doi.org/10. 1136/bmjgh-2020-004360).

Received 2 November 2020 Revised 13 February 2021 Accepted 16 March 2021

\section{Check for updates}

(C) Author(s) (or their employer(s)) 2021. Re-use permitted under CC BY-NC. No commercial re-use. See rights and permissions. Published by BMJ.

For numbered affiliations see end of article.

\section{Correspondence to} Dumisani MacDonald Hompashe; dhompashe@gmail.com

\section{ABSTRACT}

Introduction Universal Health Coverage is not only about access to health services but also about access to high-quality care, since poor experiences may deter patients from accessing care. Evidence shows that quality of care drives health outcomes, yet little is known about non-clinical dimensions of care, and patients' experience thereof relative to satisfaction with visits. This paper investigates the role of non-clinical dimensions of care in patient satisfaction.

Methods Our study describes the interactions of informed and non-informed patients with primary healthcare workers at 39 public healthcare facilities in two metropolitan centres in two South African provinces. Our analysis included 1357 interactions using standardised patients (for informed patients) and patients' exit interviews (for non-informed patients). The data were combined for three types of visits: contraception, hypertension and tuberculosis. We describe how satisfaction with care was related to patients' experiences of non-clinical dimensions.

Results We show that when real patients (RPs) reported being satisfied (vs dissatisfied) with a visit, it was associated with a $30 \%$ increase in the probability that a patient is greeted at the facilities. Likewise, when the RPs reported being satisfied (vs dissatisfied) with the visit, it was correlated with a $15 \%$ increase in the prospect that patients are pleased with healthcare workers' explanations of health conditions.

Conclusion Informed patients are better equipped to assess health-systems responsiveness in healthcare provision. Insights into responsiveness could guide broader efforts aimed at targeted education and empowerment of primary healthcare users to strengthen health systems and shape expectations for appropriate care and conduct.

\section{INTRODUCTION}

Universal Health Coverage is not only about facilitating access to health services but also more fundamentally it is about access to highquality care. ${ }^{1-3}$ While South Africa has made tremendous strides in expanding access to care since 1994, the same cannot be said about

\section{Key questions}

What is already known?

- Universal Health Coverage does not only involve healthcare access but also encompasses access to high-quality care.

- South Africa has succeeded in expanding access to care since 1994, however, the country has challenges regarding the quality of care.

- The role played by the quality of care on health outcomes is widely understood, but there is limited knowledge about health-systems responsiveness (HSR) and patients' experience of satisfaction with care.

\section{What are the new findings?}

- Non-clinical dimensions of care (grounded in HSR) as measured among informed and non-informed patients were significantly associated with an overall satisfactory experience.

- However, it was among the informed patients that greater number of HSR domains were more strongly associated with satisfaction.

What do the new findings imply?

- Informed patients are better equipped to assess health-systems responsiveness in healthcare provision.

- The findings indicate the importance of improving patients' expectations around quality of care, specifically health-systems responsiveness of the healthcare system and sharing health information with healthcare users.

the quality of care, ${ }^{4-7}$ which is important since poor experiences may deter patients from accessing care. ${ }^{8}$ Quality of care is critical given South Africa's struggle with continuity of care and adherence to treatment by patients with chronic conditions. ${ }^{9}$

Although there is evidence that quality of care plays a role in influencing health outcomes, health-systems responsiveness is not yet well understood. ${ }^{10-13}$ Elements of 
responsiveness are frequently drawn from the Donabedian framework of technical, process and structural quality. ${ }^{14}$ While technical quality is understood to encompass dimensions such as appropriateness, effectiveness and technical competence, process quality captures responsiveness dimensions such as courtesy, communication, respect, choice and autonomy. ${ }^{14}$ These aspects may determine patients' willingness to return to facilities and to continue to engage in care. ${ }^{15}$ More insight into responsiveness is necessary to improve continuity of care and promote treatment adherence.

Non-clinical dimensions of care, the focus of this study, are grounded on the concept of health-systems responsiveness (HSR). ${ }^{14} 1617$ HSR includes eight domains: dignity, prompt attention, autonomy, confidentiality, choice of provider, clear communication, social support and basic amenities. ${ }^{14}{ }^{17}$ These are categorised into interpersonal domains (dignity, autonomy, communication and confidentiality) and structural domains (quality of basic amenities, choice, access to social-support networks and prompt attention) ${ }^{18}$ Health-systems responsiveness encompasses attributes of human rights that include respecting patients' autonomy and dignity and interpersonal aspects, for instance, the quality of basic amenities. ${ }^{19}$ The WHO describes health-systems responsiveness as a universal health system goal and an indicator that can be used to evaluate how well healthcare systems respond to people's needs in non-clinical domains such as communication, autonomy and confidentiality. ${ }^{20}$ An outcome measure of HSR, together with health outcomes and confidence in the health system, is patient satisfaction. ${ }^{21}$ This indicates whether or not the care provided met the patient's needs and expectations. ${ }^{3}$

In this paper, we present evidence on HSR as related to patient satisfaction from two separate datasets. First, data from standardised patients (SPs) at public primary healthcare (PHC) facilities, and second, from patient exit interviews with real patients (RPs) at the same facilities. The SP visits provided a proxy for informed patient visits. Our data sets for RPs and SPs contain responses on overall visit satisfaction and questions related to dignity, quality of basic amenities, confidentiality and effective communication. These questions allow for the assessment of the non-clinical aspects of care that RPs value, and also how much value they attach to these aspects.

The SP method, also known as 'simulated patient', 'mock patient' or 'mystery patient' approach, is the gold standard for research of this nature. ${ }^{22-25}$ It endeavours to seek a more accurate and reliable measurement of the clinical aspects of the healthcare interaction. ${ }^{22} 2326$ Despite some shortcomings associated with the methodology such as only being feasible for easily simulated conditions, the possibility of exposing SPs to risky environments and, its limitation to situations where 'walk-ins' are acceptable, ${ }^{27}$ data from the SP method can provide far-reaching insights into healthcare quality.

In comparison with the RP data from patient exit interviews, we use novel SP data. The comparison allows for an understanding of whether the non-clinical dimensions of visits play a bigger role in determining satisfaction for SPs than for RPs. Most of the RPs visited nearby facilities that they had been to in the past, and this shows that they had prior experience of the healthcare provision. Furthermore, the comparison sheds new light on whether responsiveness continues or ceases to matter once patients have been educated in understanding the importance of clinical (technical) dimensions of quality. Insights into the responsiveness and the influence of awareness on quality could contribute to strengthening the health system and shaping expectations for appropriate care and conduct during the provider-patient interaction.

This paper is structured as follows: after describing the methods, we summarise the key findings and discuss these findings in relation to the literature. Finally, we provide a conclusion and summary.

\section{METHODS}

\section{Study setting}

The research team collected data from 39 public PHC facilities, 19 in the Cape Town metropolitan district (Western Cape Province) and 20 in Buffalo City (Eastern Cape Province) in South Africa from July 2016 to April 2017. ${ }^{47}$ All facilities in the sample are administered by the provincial departments of health. Cape Town Metro is one of the wealthiest health districts in the country, while Buffalo City metro is characterised as a less-wealthy district. ${ }^{28}$ Compared with other districts, the Cape Town metro has a significantly greater proportion of the population who have private health insurance at $24 \%$, leaving $76 \%$ relying on government-operated facilities. ${ }^{28} \mathrm{In}$ Buffalo City, $17.4 \%$ have private health insurance. ${ }^{28}$

\section{Data collection and outcomes}

We collected data using the SP and RP methods as part of the same quality of care study.

\section{SP data-collection approach}

The SP approach comprised the dispatching of concealed fieldworkers to different health facilities where they each presented with the same set of health symptoms that would trigger clinical questions, diagnoses and tests from the healthcare workers. The fieldworkers covered each of the three clinical health areas (contraception, tuberculosis (TB) and hypertension). Twenty-four were recruited for both provinces (four per clinical area per province). They were trained for 1 week to follow a script with standard questions likely to be asked by healthcare workers for each clinical area. The training emphasised that the SP should provide consistent responses during all the visits and avoid detection at the facilities. It was also emphasised that the SPs should only supply predetermined answers in response to questions asked by the healthcare worker, that is, they should not disclose any information voluntarily.

While provincial authorities alerted management of facilities to the likelihood of SP visits over a given period, 
individual healthcare workers at the facilities were not made aware that the SPs were fake patients. This type of concealment allowed researchers to capture healthcare workers' behaviour in a normal day-to-day setting and avoided problems associated with the Hawthorne effect.

The screening instruments for the three clinical health areas, the scripts and score sheets, were formulated based on publicly available documents from the international SP manual. ${ }^{29}{ }^{30}$ The scripts and score sheets were reviewed by clinical experts, PHC providers and programme managers to ensure that they reflected current best practice and conformed to the way guidelines have been interpreted and implemented at public PHC facilities. Within 1 hour of the visit, the SPs compiled notes of the interaction with the healthcare workers. A debriefing session with the fieldwork manager followed, who then audited all the SP interactions that day.

The data were collected over 6 months, largely during the second half of 2016. A sample size of 480 SP interactions (ie, $24 \mathrm{SP} \times 20$ visits) was anticipated but 464 interactions materialised. After taking into account failed visits, the exclusion of SPs home facilities and the visits for which there were missing data, 376 (81.0\%) SP observations (ie, 139 contraception visits, 94 hypertension visits and $143 \mathrm{~TB}$ visits) were available for analysis.

\section{RP data-collection approach}

Following the completion of all the SP visits, exit interviews were conducted at the same facilities visited by SPs. We aimed to conduct 2000 patient interviews at these facilities using five fieldworkers for 10 days. Like the SP study, permission for the RP data collection was obtained from provincial health authorities. The RP fieldworkers were provided with an official letter to present at each clinic before interviewing the patients. Before arrival, the fieldwork manager contacted the facility managers to obtain permission to conduct interviews on the premises.

The interviews were conducted as patients were leaving the clinic after consultation with the health workers and 1064 interviews were completed in both provinces. We could not meet our anticipated sample of 2000 due to some patients declining to participate as they were in a hurry to get home; patients who made clinic visits for health conditions that were not the focus of the study (ie, $\mathrm{TB}$, hypertension or contraception) and patients who collected medication but did not have a complete clinical interaction.

\section{Measures}

Patient satisfaction was selected as the dependent variable and was based on the general level of satisfaction experienced at facilities. Satisfaction was assessed through a question with five response categories: 'very satisfied', 'somewhat satisfied', 'neutral' (neither satisfied nor dissatisfied), 'somewhat dissatisfied' and 'very dissatisfied'. These were then classified into two broad categories: 'satisfied' (very satisfied, somewhat satisfied) and 'dissatisfied' (neutral, somewhat dissatisfied and very

\begin{tabular}{|c|c|}
\hline Domains & Non-clinical dimensions of care \\
\hline $\begin{array}{l}\text { Respect and } \\
\text { dignity }\end{array}$ & $\begin{array}{l}\text { Satisfaction with welcoming by staff at } \\
\text { the facility } \\
\text { Satisfaction with the general attitude of } \\
\text { healthcare staff at the facility }\end{array}$ \\
\hline $\begin{array}{l}\text { Quality of basic } \\
\text { amenities }\end{array}$ & $\begin{array}{l}\text { Satisfaction with the cleanliness of the } \\
\text { facility }\end{array}$ \\
\hline Confidentiality & Satisfaction with the level of privacy \\
\hline $\begin{array}{l}\text { Effective } \\
\text { communication }\end{array}$ & $\begin{array}{l}\text { Understanding of patient's problem by } \\
\text { healthcare workers } \\
\text { Satisfaction with how well the healthcare } \\
\text { worker explained the patient's health } \\
\text { condition }\end{array}$ \\
\hline
\end{tabular}

dissatisfied). The neutral category $(14.5 \%$ in the total sample: $18.9 \%$ in SPs and $10.9 \%$ in RPs) was entered in the 'dissatisfied' option as patients (real or standardised) who answered that they were 'neither satisfied nor dissatisfied' were not able to categorise a satisfactory response with the health services.

The study's independent variables were the non-clinical dimensions of healthcare, converted to a dichotomous scale (satisfied and dissatisfied). HSR on non-clinical dimensions of care was organised into four groups (see table 1).

The analysis also included the following patient sociodemographic covariates: sex (female, male); age; race; education (<matric, matric, $>$ matric), region of residence (Eastern Cape Province and Western Cape Province) and asset variables (possession of a motor car or van and possession of refrigerator or freezer). Due to the small sample size, we did not limit the analysis to observations for which complete data were available.

\section{Statistical analysis}

We used descriptive statistics to analyse patient characteristics and responsiveness with healthcare. In addition to questions that capture the respondents' background information (both SPs and RPs), other questions asked respondents to indicate their satisfaction with how healthcare workers behaved during the clinical interaction. We conducted a bivariate analysis, including $\chi^{2}$ tests, between the dependent variable (patient satisfaction) and each independent variable (patient responsiveness to nonclinical dimensions of care) for RPs, to measure the pure association between these variables. We estimated a linear probability model to examine how satisfaction with overall care was related to the non-clinical dimensions of care. We ran two multivariate regression models for RP and SP analyses, respectively, while controlling for potential confounders.

\section{Patient and public involvement}

Meetings were convened with officials from the two Provincial Departments of Health to discuss study design 


\begin{tabular}{|c|c|c|c|c|}
\hline \multirow[b]{3}{*}{ Characteristic } & \multirow{2}{*}{\multicolumn{2}{|c|}{$\begin{array}{l}\text { RP sample } \\
(n=1021)\end{array}$}} & \multirow{2}{*}{\multicolumn{2}{|c|}{$\begin{array}{l}\text { SP sample } \\
(n=336)\end{array}$}} \\
\hline & & & & \\
\hline & Mean & (SE) & Mean & (SE) \\
\hline \multicolumn{5}{|l|}{ Gender } \\
\hline Female & 0.32 & $(0.02)$ & 0.69 & $(0.03)$ \\
\hline Age & 34.6 & $(0.58)$ & 33.0 & $(0.54)$ \\
\hline $15-29$ years & 0.29 & $(0.01)$ & 0.63 & $(0.03)$ \\
\hline$\geq 30$ years & 0.71 & $(0.01)$ & 0.37 & $(0.03)$ \\
\hline \multicolumn{5}{|l|}{ Province } \\
\hline Eastern Cape & 0.48 & $(0.02)$ & 0.53 & $(0.03)$ \\
\hline \multicolumn{5}{|l|}{ Race } \\
\hline Black African & 0.74 & $(0.01)$ & 0.77 & $(0.02)$ \\
\hline \multicolumn{5}{|l|}{ Education } \\
\hline Primary & 0.63 & $(0.02)$ & 0.24 & $(0.02)$ \\
\hline Secondary & 0.27 & $(0.01)$ & 0.20 & $(0.02)$ \\
\hline Tertiary & 0.10 & $(0.01)$ & 0.56 & $(0.03)$ \\
\hline \multicolumn{5}{|l|}{ Non-clinical variables } \\
\hline Welcoming by staff & 0.79 & $(0.01)$ & 0.50 & $(0.03)$ \\
\hline $\begin{array}{l}\text { General attitude of } \\
\text { staff }\end{array}$ & 0.78 & $(0.01)$ & 0.62 & $(0.03)$ \\
\hline $\begin{array}{l}\text { Satisfaction with } \\
\text { cleanliness of the } \\
\text { facility }\end{array}$ & 0.77 & $(0.01)$ & 0.57 & $(0.03)$ \\
\hline Level of privacy & 0.88 & $(0.01)$ & 0.60 & $(0.03)$ \\
\hline $\begin{array}{l}\text { Understanding of } \\
\text { patient's problem by } \\
\text { staff }\end{array}$ & 0.90 & $(0.01)$ & 0.62 & $(0.03)$ \\
\hline $\begin{array}{l}\text { How well healthcare } \\
\text { workers explained } \\
\text { the patient's health } \\
\text { condition }\end{array}$ & 0.78 & $(0.01)$ & 0.28 & $(0.02)$ \\
\hline
\end{tabular}

$\mathrm{RP}$, real patient; SP, standardised patient.

and research questions. Advices were solicited from clinical professionals, public-health experts and programme managers for the design of the scripts for the three clinical areas in both provinces. Training conducted with SPs allowed for sharing of experiences and preferences regarding the utilisation of healthcare at PHC facilities. Such experiences were considered in the design of the research instruments.

\section{RESULTS}

Of the 1021 RPs, 324 (32\%) were women, and 729 (71\%) were aged 30 years and above (table 2). Regarding education level, $104(10 \%)$ of the RP respondents had tertiary education, $276(27 \%)$ had secondary education and 641 (63\%) had primary education. Most RPs were black Africans $(74 \%)$ and only 490 (48\%) had the Eastern Cape as their province of residence. Concerning the SP sample,

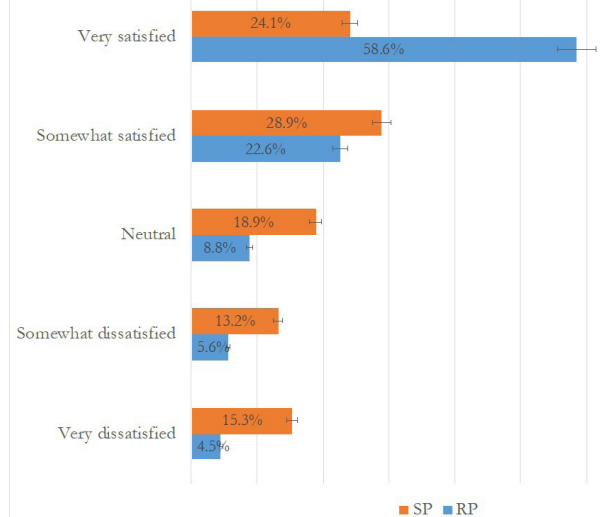

Figure 1 Distribution of overall satisfaction scores for SPs and RPs. RP, realpatient; SP, standardised patient.

$232(69 \%)$ were women, while $212(63 \%)$ ranged in age from 15 to 29 years. Of the 336 SPs, more than half (56\%) had some type of tertiary qualification, 178 (52\%) resided in the Eastern Cape and 258 (77\%) were black Africans (table 2).

For non-clinical quality of care, 809 (79\%) RPs were reportedly satisfied with being greeted and welcomed at the facilities. Likewise, 796 (78\%) RPs expressed satisfaction with the general attitude of healthcare workers. In terms of the cleanliness of facilities, the level of privacy, healthcare workers' understanding of patients' problems and explanation of the patients' health conditions, the RPs were also reportedly highly satisfied. However, the satisfaction scores of SPs were relatively lower in all the non-clinical measures, ranging from $28 \%$ to $62 \%$ (table 2).

\section{Patient satisfaction with overall care at facilities}

Out of 1021 RPs, only 46 (4.5\%) were 'very dissatisfied' with the overall care at facilities (figure 1) while 57 (5.6\%) were 'somewhat dissatisfied', 598 (58.6\%) were 'very satisfied' and $230(22.6 \%)$ were 'somewhat satisfied'. The remaining 90 (8.8\%) RPs were neutral.

Figure 1 shows that SPs had a fewer number of visits in which they were 'very satisfied' than RPs. The low numbers are attributed to the empowerment SPs received during their training on providers' clinical guidelines. The training sensitised these fake patients about what healthcare workers ought to do during provider-patient interactions, which was not the case for the RPs. Hence, SPs were better informed than RPs and may have been more critical in their assessment of healthcare providers.

Table 3 provides the results of Pearson's $\chi^{2}$ test. In the RP sample, patients who were satisfied with non-clinical aspects of care were more likely to report being satisfied with the overall care received at the facilities. Nine out of 10 RPs were satisfied with being greeted and welcomed at the facilities compared with about 4 out of 10 who expressed dissatisfaction with welcoming. This was significant $\left(\chi^{2}(1, \mathrm{~N}=1021)=317.93, \mathrm{p}=0.000\right)$. Regarding the general attitude at the facilities, more than $90 \%$ of RPs 
Table 3 Bivariate results of RP experiences with non-clinical factors related to satisfaction with overall care $(n=1021)$

\begin{tabular}{|c|c|c|c|c|}
\hline & $\begin{array}{l}\text { Satisfaction relative } \\
\text { to non-observance } \\
\text { of non-clinical care }\end{array}$ & $\begin{array}{l}\text { Satisfaction relative } \\
\text { to observance of } \\
\text { non-clinical care }\end{array}$ & $\mathbf{X}^{2}$ & $P$ value \\
\hline \multicolumn{5}{|l|}{ Respect and dignity } \\
\hline How satisfied are you with welcoming by staff? & $83(39.2 \%)$ & $749(92.6 \%)$ & 317.93 & $0.000^{\star \star \star}$ \\
\hline $\begin{array}{l}\text { How satisfied are you with the general attitude of } \\
\text { staff? }\end{array}$ & $94(42.3 \%)$ & $738(92.4 \%)$ & 288.19 & $0.000^{* * *}$ \\
\hline \multicolumn{5}{|l|}{ Quality of basic amenities } \\
\hline $\begin{array}{l}\text { How satisfied are you with the cleanliness of the } \\
\text { facility? }\end{array}$ & $149(62.6 \%)$ & $683(87.2 \%)$ & 73.36 & $0.000^{* * *}$ \\
\hline \multicolumn{5}{|l|}{ Confidentiality } \\
\hline How satisfied are you with the level of privacy? & $68(53.5 \%)$ & $764(85.5 \%)$ & 75.09 & $0.000^{\star \star \star}$ \\
\hline \multicolumn{5}{|l|}{ Effective communication } \\
\hline Did the healthcare worker understand your problem? & $49(48.5 \%)$ & $783(85.1 \%)$ & 80.79 & $0.000^{\star * *}$ \\
\hline $\begin{array}{l}\text { How satisfied are you with how well the healthcare } \\
\text { worker explained your health condition? }\end{array}$ & $112(50.2 \%)$ & $720(90.2 \%)$ & 184.88 & $0.000^{\star * \star}$ \\
\hline
\end{tabular}

${ }^{*} \mathrm{p}<0.05 ;{ }^{* *} \mathrm{p}<0.01 ;{ }^{\star \star *} \mathrm{p}<0.001$.

were satisfied, relative to slightly more than two-fifths of RPs who were not happy with this non-clinical aspect of care $\left(\chi^{2}(1, \mathrm{~N}=1021)=288.19, \mathrm{p}=0.000\right)$. More than four-fifths of RPs reported being satisfied with the cleanliness of the facilities, compared with 6 out of 10 who were not pleased with the hygiene at the facilities $\left(\chi^{2}(1\right.$, $\mathrm{N}=1021)=73.36, \mathrm{p}=0.000)$. Concerning the general level of privacy, more than four-fifths of the RPs were satisfied, relative to more than half who were not satisfied $\left(\chi^{2}(1\right.$, $\mathrm{N}=1021)=75.09$, p.0.000). More than $80 \%$ of the RPs felt satisfied with the healthcare workers' understanding of their health problem, compared with almost $50 \%$ who were not pleased with the non-clinical aspects of care $\left(\chi^{2}\right.$ $(1, \mathrm{~N}=1021)=80.79, \mathrm{p}=0.000)$. Finally, more than $90 \%$ of the RPs expressed satisfaction with the healthcare workers' explanation of their health condition versus $50 \%$ who indicated otherwise.

\section{Relationship between satisfaction with overall care and nonclinical quality of care}

We present the results according to the analysed healthsystems responsiveness domains.

\section{Respect and dignity}

Table 4 analyses the correlation between whether patients reported their consultation as 'very satisfactory' and 'somewhat satisfactory' and various aspects of nonclinical quality, controlling for socioeconomic status and patient characteristics. We show that when RPs reported being satisfied (vs dissatisfied) with the visit, this was associated with a $30 \%$ increase in the probability that a patient was satisfied with being greeted at the facilities $(p<0.01)$. When the RPs reported being satisfied (vs dissatisfied) with the visit, this was associated with a $22 \%$ increase in the probability that patients were satisfied with the general attitude at the facilities $(p<0.01)$. Regarding the SPs, the results show that being satisfied (vs dissatisfied) with the visit was correlated with a $15 \%$ (half of RPs' probability increase) increase in the patient's likelihood to be satisfied with being greeted at the facilities $(p<0.05)$. There was no statistically significant association between an SP reporting being satisfied (vs dissatisfied) with the visit and the general attitude at the facilities.

\section{Quality of basic amenities}

We measured patients' experiences about cleanliness by asking them about the extent of their satisfaction with cleanliness or hygiene of the facility. We did not find a statistically significant association between responsiveness and cleanliness for both RPs and SPs.

\section{Confidentiality}

Experiences regarding confidentiality were determined by asking patients about their degree of satisfaction with the level of privacy in counselling and testing rooms. When the RPs reported satisfied (vs dissatisfied) with the overall visit, this was associated with a $7 \%$ increase in the probability $(\mathrm{p}<0.1)$ that the patients were satisfied with the level of privacy at the facilities. Conversely, when the SPs reported being satisfied (vs dissatisfied) with the visit, this was correlated with a $16 \%$ (more than double the size of RPs' probability) increase in patients' likelihood of satisfaction with the level of privacy $(\mathrm{p}<0.01)$ (table 4$)$.

\section{Effective communication}

Table 4 shows that when the RPs reported being satisfied (vs dissatisfied) with the visit, this was associated with a $10 \%$ increase in patients' likelihood of satisfaction with the healthcare workers' understanding of patients' health problems $(p<0.05)$. Likewise, when the RPs reported being satisfied (vs dissatisfied) with the visit, 
Table 4 Linear regression results examining non-clinical and socio-demographic factors as predictors of overall patient satisfaction (SP and RP)

\begin{tabular}{|c|c|c|c|c|}
\hline \multirow[b]{2}{*}{ Variables } & \multicolumn{2}{|c|}{$\begin{array}{l}\text { Dependent } \\
\text { variable }\end{array}$} & \multicolumn{2}{|c|}{$\begin{array}{l}\text { Satisfaction with } \\
\text { general care }\end{array}$} \\
\hline & \multicolumn{2}{|l|}{$\mathbf{R P}$} & \multicolumn{2}{|l|}{ SP } \\
\hline \multicolumn{5}{|l|}{ Respect and dignity } \\
\hline \multirow[t]{2}{*}{ Welcome } & $0.301^{\star \star \star}$ & $(0.049)$ & $0.149^{\star \star}$ & $(0.063)$ \\
\hline & $(1.77)$ & & $(1.53)$ & \\
\hline \multirow[t]{2}{*}{ General attitude } & $0.220^{\star \star \star}$ & $(0.047)$ & 0.056 & $(0.074)$ \\
\hline & $(1.30)$ & & $(1.60)$ & \\
\hline \multicolumn{5}{|c|}{ Quality of basic amenities } \\
\hline \multirow[t]{2}{*}{ Cleanliness } & -0.013 & $(0.036)$ & 0.058 & $(0.049)$ \\
\hline & $(1.76)$ & & $(1.66)$ & \\
\hline \multicolumn{5}{|l|}{ Confidentiality } \\
\hline \multirow[t]{2}{*}{ Level of privacy } & $0.073^{*}$ & $(0.043)$ & $0.163^{\star \star \star}$ & $(0.049)$ \\
\hline & $(1.21)$ & & $(1.25)$ & \\
\hline \multicolumn{5}{|c|}{ Effective communication } \\
\hline \multirow{2}{*}{$\begin{array}{l}\text { Understanding } \\
\text { health problem }\end{array}$} & $0.097^{\star *}$ & $(0.042)$ & $0.310^{* \star *}$ & $(0.066)$ \\
\hline & $(1.16)$ & & $(1.45)$ & \\
\hline \multirow{2}{*}{$\begin{array}{l}\text { Explaining health } \\
\text { condition }\end{array}$} & $0.148^{\star \star \star}$ & $(0.037)$ & $0.292^{\star \star \star}$ & $(0.070)$ \\
\hline & $(1.53)$ & & $(1.42)$ & \\
\hline \multicolumn{5}{|l|}{ Socio-demographic } \\
\hline \multicolumn{5}{|c|}{ Age (Ref. from 15 to 29 years) } \\
\hline \multirow[t]{2}{*}{$\geq 30$ years } & 0.022 & $(0.022)$ & -0.009 & $(0.047)$ \\
\hline & $(1.14)$ & & $(1.35)$ & \\
\hline \multicolumn{5}{|l|}{ Gender (Ref. Male) } \\
\hline \multirow[t]{2}{*}{ Female } & 0.025 & $(0.021)$ & -0.084 & $(0.058)$ \\
\hline & $(1.03)$ & & $(1.86)$ & \\
\hline \multicolumn{5}{|l|}{ Race (Ref. African) } \\
\hline \multirow[t]{2}{*}{ Coloured } & -0.005 & $(0.033)$ & -0.073 & $(0.074)$ \\
\hline & $(1.19)$ & & $(2.10)$ & \\
\hline \multicolumn{5}{|c|}{ Education (Ref. <Matric) } \\
\hline \multirow[t]{2}{*}{ Matric } & $0.045^{\star \star}$ & $(0.021)$ & 0.063 & $(0.064)$ \\
\hline & $(1.25)$ & & $(2.39)$ & \\
\hline \multirow[t]{2}{*}{$>$ Matric } & 0.027 & $(0.035)$ & -0.111 & $(0.074)$ \\
\hline & $(1.24)$ & & (3.49) & \\
\hline \multicolumn{5}{|c|}{ Province (Ref. Eastern Cape) } \\
\hline Western Cape & 0.043 & $(0.028)$ & 0.017 & $(0.060)$ \\
\hline & $(1.28)$ & & $(1.78)$ & \\
\hline Motor vehicle or & -0.012 & $(0.027)$ & $0.134^{*}$ & $(0.067)$ \\
\hline & $(1.26)$ & & $(2.33)$ & \\
\hline Fridge or freezer & -0.031 & $(0.036)$ & -0.130 & $(0.117)$ \\
\hline & $(1.13)$ & & $(1.55)$ & \\
\hline Constant & $0.117^{\star *}$ & $(0.058)$ & 0.181 & $(0.150)$ \\
\hline Clusters (facilities) & 39 & & 39 & \\
\hline
\end{tabular}

Continued
Table 4 Continued

\begin{tabular}{|c|c|c|}
\hline & $\begin{array}{l}\text { Dependent } \\
\text { variable }\end{array}$ & $\begin{array}{l}\text { Satisfaction with } \\
\text { general care }\end{array}$ \\
\hline Variables & $\mathbf{R P}$ & SP \\
\hline Observations (visits) & 1021 & 336 \\
\hline $\mathrm{R}^{2}$ & 0.414 & 0.436 \\
\hline $\begin{array}{l}\text { Variance Inflation } \\
\text { Factors (VIF) (average) }\end{array}$ & 1.30 & 1.84 \\
\hline
\end{tabular}

Robust standard errors adjusted for clustering at the facility level shown in parentheses. Significance at ${ }^{* *} 1 \%$ level ${ }^{*} 5 \%$ level ${ }^{*} 10 \%$ level. Control variables include age, gender, race, education, province, motor vehicle or bakkie, satellite dish and fridge or freezer. VIF are provided in square brackets below the coefficients. They show that multicollinearity is not a problem in the model as the VIF values for all explanatory variables are less than 5.

RP, real patient; SP, standardised patient; VIF, variance inflation factor.

this was correlated with a $15 \%$ increase in the probability that patients will be satisfied with healthcare workers' explanation of the patients' health condition $(p<0.01)$. However, when the SPs reported being satisfied (vs dissatisfied) with the visit, this was associated with a $31 \%$ (three times more than the RPs probability) increase in the likelihood of being satisfied with healthcare workers' understanding of patients' problems $(\mathrm{p}<0.01)$. Similarly, when the SPs reported being satisfied (vs dissatisfied) with the visit, this was related to a $29 \%$ rise in patients' probability to be satisfied with healthcare workers' explanation of health condition $(\mathrm{p}<0.01)$.

Since SPs visited several facilities, it is reasonable to assume that their exposure to a wider variety of facilities might have affected their evaluation of non-clinical dimensions of care. However, after analysing the correlation of non-clinical variables (separately) with the number of SP visits done (visit sequence), there was no significant association.

\section{Sensitivity analysis}

As a robustness check, we estimated an additional model where we included a clinical (technical) quality variable as one of the explanatory variables. This check was done to determine whether the clinical quality variable is a complement or substitute for the non-clinical variables. This variable captured whether healthcare workers asked a question about the patient's previous illness or condition (online supplemental table S1). Clinical protocols require healthcare workers to enquire about patients' medical history during clinical interactions.

The results remained robust as the same non-clinical variables were significant in both RPs and SPs, except for the general level of privacy and healthcare workers' understanding of health problem, which were not significant (online supplemental table S1). 
DISCUSSION

The aim of any health system is to provide patients with high-quality care to drive demand for services and ultimately improve health outcomes. ${ }^{31}$ Patients who are satisfied with the services they receive from healthcare providers are likely to seek more healthcare than those who are less satisfied ${ }^{32}$ and also at the appropriate time that they require care. It is, therefore, important to understand if the non-clinical dimensions of healthcare are more or less important to SPs compared with RPs, given the training SPs received to enable the systematic measurement of clinical (technical) quality experienced during their visits. More specifically, it is critical to determine what RPs value in their healthcare, and how much of that is intrinsically valued versus simply being understood as a signal for quality.

In general, our findings reveal that more positive interactions with the non-clinical factors were significantly associated with an overall satisfactory experience with the health services for both the RPs and SPs. Moreover, findings suggest that the following non-clinical aspects of quality matter to RPs: being greeted and welcomed at facilities, the general attitude of facility staff, healthcare workers' understanding of patients' health problems and the healthcare workers' explanation of patients' health conditions. RPs' attaching greater value to these aspects of quality could be explained by a context in which many patients are not well treated by healthcare workers. Household survey respondents in South Africa report rudeness by healthcare workers as one of the deterrents to healthcare access. ${ }^{33}$ Consequently, in addition to the medical or technical aspects of healthcare, policymakers should also focus on non-clinical factors to ensure that patients are satisfied with the public health service ${ }^{34}$ and increase the possibility of further future engagements. The findings should be considered relative to the idea that the positivity of the patients does not in any way suggest that quality was very high, nor does it mean that patients were really satisfied with the quality of care they received. $^{35}$

We also found that among SPs, the more non-clinical dimensions of healthcare were strongly related to patient satisfaction with overall care, while fewer of these dimensions were significant among RPs. Respect for dignity was the only dimension that was strongly associated with satisfaction among RPs. The noteworthy dimensions for the SPs were confidentiality and effective communication and these were strongly related to clinical quality. There is literature that shows that patients' experience of being given no explanation about their disease and not keeping information confidential is associated with loss to follow-up. ${ }^{36}$ Another study also found the explanation of illness and appropriate treatment by clinicians to be very important to patients. ${ }^{37}$ The literature shows that a clear explanation of the diagnosis and good staff attitudes were among the important attributes determining health-seeking behaviour. ${ }^{37}$
In addition to organisational aspects such as welcoming and greeting by staff and cleanliness of the facility, SPs also consider interpersonal attributes of non-clinical care (such as healthcare workers' understanding of their health condition) vital in their evaluation of healthcare quality. Most of the interpersonal attributes include effective communication on the part of healthcare providers. In a recent study, the lack of effective communication is highlighted as one of the impediments of South Africa's PHC system. ${ }^{4}$ The authors point out that failure to communicate with patients does not only lead to poor case management but also indicates a lack of patientcentredness and responsiveness. This implies a need for policymakers to pay attention to the way healthcare workers communicate as part of their professional development programmes.

In contrast to the findings of this study, evidence from informed patients' studies shows that informed patients report better care experiences compared with non-informed patients. ${ }^{38}$ This might be attributed to the fact that informed patients have the skills and confidence to seek what they need from their providers. ${ }^{38} 39$ In our study, it was the non-informed patients (RPs) who reported better care experiences overall. Social desirability bias (not wanting to disappoint enumerators), prior limited care experiences (not having been exposed to good care before) and lower education levels might have influenced them to report higher scores although services might have been of lower quality as noted in the literature. $^{4041}$

Patient characteristics such as gender, age, race and province were not significantly associated with patient satisfaction in our study. This is contrary to other studies that found that characteristics such as age, race or ethnicity, income and education were related to how patients rate their care experience. ${ }^{39}{ }^{42-44}$ However, in the sensitivity analysis, being female was significantly associated with patient satisfaction among SPs, whereas younger age had a significant association with satisfaction among RPs. Well-educated patients may be able to understand and evaluate the care received better. ${ }^{45}$ Significant differences in overall satisfaction with healthcare services by race and income could be attributed to differences in the ability to access private healthcare services among the population groups and limited care experiences of respondents. ${ }^{32}$ In our study, this suggests that the race of patients (only black African and coloured) might be insignificantly associated with satisfaction because the study was confined to the public healthcare services, where patients may not always experience a wide variety of quality of care.

It is worth noting that high-school completion was significantly related to satisfaction only among SPs. It is not clear whether more education means patients were objectively better treated by healthcare workers or were able to better evaluate the non-clinical nature of care received. This finding is in line with studies that found that more education was positively associated with patient 
satisfaction. ${ }^{42} 43$ However, in our study, this implies that education may be important, not only for its own sake but also for patient empowerment.

Our findings should be interpreted with caution due to the following limitations. First, our main limitation is the sample size of 39 healthcare facilities in only two provinces and the limited number of visits conducted at each facility. Second, our study was only based on urban areas and, therefore, the findings cannot be generalised. Third, this study is restricted to patients who visited healthcare facilities during the study period. Fourth, the cross-sectional nature of our data did not allow us to follow the SPs to investigate the benefits of their awareness and their health-seeking behaviour.

The findings from the robustness test also showed that in healthcare areas, HSR indicators such as welcoming and greeting by staff, the attitude of staff and healthcare workers' explanation of patients' health condition, are complementary to clinical quality. These are non-clinical quality indicators that RPs intrinsically value, as opposed to the general level of privacy and healthcare workers' understanding of health problem, which seem to be mere signals for quality. Healthcare workers should, therefore, consider both clinical and nonclinical dimensions of care not only when treating patients but also when focussing on technical care.

\section{CONCLUSION}

Our results suggest that informed patients are better equipped to assess health-systems responsiveness in healthcare provision. This is an important finding given the need for improved accountability and clinical governance in the health system. In general, the findings show that it is critical to improve patients' expectations around the quality of care, specifically HSR of the healthcare system and acknowledge the importance of sharing health information with healthcare users. Insights into responsiveness could guide broader efforts aimed at targeted education of PHC users to strengthen the health systems and shape expectations for appropriate care and conduct.

\section{Author affiliations}

${ }^{1}$ Economics, University of Fort Hare Faculty of Management and Commerce, Alice, South Africa

${ }^{2}$ Economics, Stellenbosch University Faculty of Economic and Management Sciences, Stellenbosch, South Africa

${ }^{3}$ Economics, Lund University, Lund, Sweden

${ }^{4}$ Economics, University of the Western Cape, Cape Town, South Africa

Twitter Dumisani MacDonald Hompashe @dumzaro_,Carmen S Christian @carmensuechrlop, Anja Smith @anja_M_Smith and Ronelle Burger @Ronelle_B

Acknowledgements We would like to thank the Provincial Departments of Health in the Eastern Cape and Western Cape Provinces of South Africa for permitting us to conduct the study. We are grateful to Prof Servaas Van der Berg and the Research for Socio-Economic Policy (ReSEP) group at Stellenbosch University for guidance and inputs on the paper.

Contributors The study was designed and conceived by RB, UGG, AS, CSC and DMH. DMH, AS, CSC and RB oversaw the data collection. DMH drafted the manuscript and AS, RB, UGG and CSC proofread, edited and provided critical review and comments on the manuscript.

Funding The research was supported by the National Research Foundation of South Africa and the South African Medical Research Council (grant numbers: TTK150605118774, CPRR150722129596, SDG160531166953, UID86895, RCA13102556861).

Competing interests None declared.

Patient consent for publication Not required.

Ethics approval We received ethics clearance from the Humanities Research Ethics Committee (HREC) of Stellenbosch University (approval \#HS10964) and received permission to conduct this research in public primary care facilities from the provincial departments of health. The concealed nature of the SP method is permissible if the concealment is necessary for the research. Written informed consent was obtained from patients interviewed in the facilities.

Provenance and peer review Not commissioned; externally peer reviewed.

Data availability statement Data are available upon request. Individual de-identified data will be available on reasonable request. All variables needed to recreate the results reported in this article will be included, as will the code required to reproduce these results. The data and code can be accessed through email request to the first author.

Supplemental material This content has been supplied by the author(s). It has not been vetted by BMJ Publishing Group Limited (BMJ) and may not have been peer-reviewed. Any opinions or recommendations discussed are solely those of the author(s) and are not endorsed by BMJ. BMJ disclaims all liability and responsibility arising from any reliance placed on the content. Where the content includes any translated material, BMJ does not warrant the accuracy and reliability of the translations (including but not limited to local regulations, clinical guidelines, terminology, drug names and drug dosages), and is not responsible for any error and/or omissions arising from translation and adaptation or otherwise.

Open access This is an open access article distributed in accordance with the Creative Commons Attribution Non Commercial (CC BY-NC 4.0) license, which permits others to distribute, remix, adapt, build upon this work non-commercially, and license their derivative works on different terms, provided the original work is properly cited, appropriate credit is given, any changes made indicated, and the use is non-commercial. See: http://creativecommons.org/licenses/by-nc/4.0/.

\section{ORCID iDs}

Dumisani MacDonald Hompashe http://orcid.org/0000-0002-5652-719X

Ulf-G Gerdtham https://orcid.org/0000-0002-0647-7817

Carmen S Christian https://orcid.org/0000-0003-4740-6501

Anja Smith https://orcid.org/0000-0003-3135-4146

Ronelle Burger https://orcid.org/0000-00003-2463-5265

\section{REFERENCES}

1 Jha A, Godlee F, Abbasi K. Delivering on the promise of universal health coverage. BMJ 2016;353:i2216.

2 Kruk ME, Ataguba JE, Akweongo P. The universal health coverage ambition faces a critical test. Lancet 2020;396:1130-1. doi:10.1016/ S0140-6736(20)31795-5

3 Kruk ME, Gage AD, Arsenault C, et al. High-quality health systems in the sustainable development goals era: time for a revolution. Lancet Glob Health 2018;6:e1196-252 https://linkinghub.elsevier.com/ retrieve/pii/S2214109X18303863

4 Burger R, Christian CS, Gerdtham U-G, et al. Use of simulated patients to assess hypertension case management at public healthcare facilities in South Africa. J Hypertens 2020;38:362-7.

5 Burger R, Christian C. Access to health care in post-apartheid South Africa: availability, affordability, acceptability. Health Econ Policy Law 2020;15:1-13.

6 Gilson L, Mclntyre D. Post-apartheid challenges: household access and use of health care in South Africa. Int J Health Serv 2007;37:673-91.

7 Christian CS, Gerdtham U-G, Hompashe D, et al. Measuring quality gaps in TB screening in South Africa using standardised patient analysis. Int J Environ Res Public Health 2018;15:729-10.

8 Nxumalo N, Goudge J, Manderson L. Community health workers, recipients' experiences and constraints to care in South Africa - a pathway to trust. AIDS Care 2016;28:61-71.

9 Fernandez-Lazaro Cl, García-González JM, Adams DP, et al. Adherence to treatment and related factors among patients with 
chronic conditions in primary care: a cross-sectional study. BMC Fam Pract 2019;20:1-12.

10 Brinkerhoff DW, Bossert TJ. Health governance: principal-agent linkages and health system strengthening. Health Policy Plan 2014;29:685-93.

11 Cleary SM, Molyneux S, Gilson L. Resources, attitudes and culture: an understanding of the factors that influence the functioning of accountability mechanisms in primary health care settings. BMC Health Serv Res 2013;13:320.

12 Hajjaj FM, Salek MS, Basra MKA, et al. Non-clinical influences on clinical decision-making: a major challenge to evidence-based practice. J R Soc Med 2010;103:178-87.

13 Mirzoev T, Kane S. What is health systems responsiveness? Review of existing knowledge and proposed conceptual framework. BMJ Glob Health 2017;2:e000486-11.

14 Valentine N, de Silva A, Kawabata K. Health system responsiveness: concepts, domains, and operationalization 2003;2003:573-96.

15 World Health Organization. Patient engagement: technical series on safer primary care. side effects of drugs annual. Geneva, 2016.

16 World Health Organization. The world health report 2000 - health systems: improving performance. WHO Library Cataloguing in publication Data. Geneva, 2000.

17 Liabsuetrakul T, Petmanee P, Sanguanchua S, et al. Health system responsiveness for delivery care in southern Thailand. Int J Qual Health Care 2012;24:169-75.

18 Ebrahimipour H, Vafaei Najjar A, Khani Jahani A, et al. Health system responsiveness: a case study of general hospitals in Iran. Int $J$ Health Policy Manag 2013;1:85-90.

19 Robone S, Rice N, Smith PC. Health systems' responsiveness and its characteristics: a cross-country comparative analysis. Health Serv Res 2011;46:2079-100.

20 De Silva A. A framework for measuring responsiveness. World Health Organisation, 2000.

21 Larson E, Sharma J, Bohren MA, et al. When the patient is the expert: measuring patient experience and satisfaction with care. Bull World Health Organ 2019;97:563-9.

22 Daniels B, Dolinger A, Bedoya G, et al. Use of standardised patients to assess quality of healthcare in Nairobi, Kenya: a pilot, crosssectional study with international comparisons. BMJ Glob Health 2017;2:e000333-11.

23 Das J, Kwan A, Daniels B, et al. Use of standardised patients to assess quality of tuberculosis care: a pilot, cross-sectional study. Lancet Infect Dis 2015;15:1305-13.

24 Peabody JW, Luck J, Glassman P, et al. Comparison of vignettes, standardized patients, and chart abstraction. JAMA 2000;283:1715-22.

25 Wiseman V, Lagarde M, Kovacs R, et al. Using unannounced standardised patients to obtain data on quality of care in low-income and middle-income countries: key challenges and opportunities. BMJ Glob Health 2019;4:e001908-3.

26 Das J, Holla A, Das V, et al. In urban and rural India, a standardized patient study showed low levels of provider training and huge quality gaps. Health Aff 2012;31:2774-84.

27 Holla A. Measuring the quality of health care in clinics [online]. Washington, DC, 2013. Available: https://www.globalhealthlearning. org/sites/default/files/page-files/Measuring Quality of Health Care 020313.pdf

28 Massyn N, Padarath A, Peer N. District Health Barometer 2016/17 [online]. Health Systems Trust, 2017: 1-839. http://www.hst.org.za/
publications/District Health Barometers/District Health Barometer 2016-2017.pdf\%0Ahttp://www.hst.org.za

29 National Department of Health. National tuberculosis management guidelines 2014. Pretoria: Republic of South Africa, 2014: 1-116.

30 South African National Department of Health. National guide on primary prevention of chronic diseases of lifestyle (CDL), 2005.

31 Dansereau E, Masiye F, Gakidou E, et al. Patient satisfaction and perceived quality of care: evidence from a cross-sectional national exit survey of HIV and non-HIV service users in Zambia. BMJ Open 2015;5:e009700-11.

32 Jacobsen KH, Hasumi T. Satisfaction with healthcare services in South Africa: results of the National 2010 general household survey. Pan Afr Med J 2014;18:1-11.

33 Burger R, Bredenkamp C, Grobler C, et al. Have public health spending and access in South Africa become more equitable since the end of apartheid? Dev South Afr 2012;29:681-703.

34 Fernández-Pérez Ángel, Sánchez Ángeles, Sánchez A. Improving people's self-reported experience with the health services: the role of non-clinical factors. Int J Environ Res Public Health 2019;17

35 Leonard KL. Is patient satisfaction sensitive to changes in the quality of care? An exploitation of the Hawthorne effect. $J$ Health Econ 2008:27:444-59.

36 Cazabon D, Pande T, Sen P, et al. User experience and patient satisfaction with tuberculosis care in low- and middle-income countries: a systematic review. J Clin Tuberc Other Mycobact Dis 2020;19:100154.

37 Honda A, Ryan M, van Niekerk R, et al. Improving the public health sector in South Africa: eliciting public preferences using a discrete choice experiment. Health Policy Plan 2015;30:600-11.

38 Hibbard JH, Greene J. What the evidence shows about patient activation: better health outcomes and care experiences; fewer data on costs. Health Aff 2013;32:207-14.

39 Hibbard JH, Stockard J, Mahoney ER, et al. Development of the patient activation measure (PAM): conceptualizing and measuring activation in patients and consumers. Health Serv Res 2004;39:1005-26.

40 Jafari Kelarijani SE, Jamshidi R, Heidarian AR, et al. Evaluation of factors influencing patient satisfaction in social security hospitals in Mazandaran Province, North of Iran. Caspian J Intern Med 2014;5:232-4.

41 Latkin CA, Edwards C, Davey-Rothwell MA, et al. The relationship between social desirability bias and self-reports of health, substance use, and social network factors among urban substance users in Baltimore, Maryland. Addict Behav 2017;73:133-6.

42 Carlson MJ, Blustein J, Fiorentino N, et al. Socioeconomic status and dissatisfaction among $\mathrm{HMO}$ enrollees. Med Care 2000;38:508-16.

43 Elliott MN, Zaslavsky AM, Goldstein E, et al. Effects of survey mode, patient mix, and nonresponse on CAHPS Hospital survey scores. Health Serv Res 2009;44:501-18.

44 Weech-Maldonado R, Morales LS, Elliott M, et al. Race/ethnicity, language, and patients' assessments of care in Medicaid managed care. Health Serv Res 2003;38:789-808.

45 Valentine N, Verdes-Tennant E, Bonsel G. Health systems' responsiveness and reporting behaviour: Multilevel analysis of the influence of individual-level factors in 64 countries. Soc Sci Med 2015;138:152-60. 